\title{
Lugano Classification Stage IIE Adult Non- Hodgkin Lymphoma AJCC v8
}

National Cancer Institute

\section{Source}

National Cancer Institute. Lugano Classification Stage IIE Adult Non-Hodgkin Lymphoma

A/CC v8. NCl Thesaurus. Code C141163.

Stage IIE: Contiguous extralymphatic extension from a nodal site with or without involvement of other lymph node regions on the same side of the diaphragm. (from AJCC 8th Ed.) 